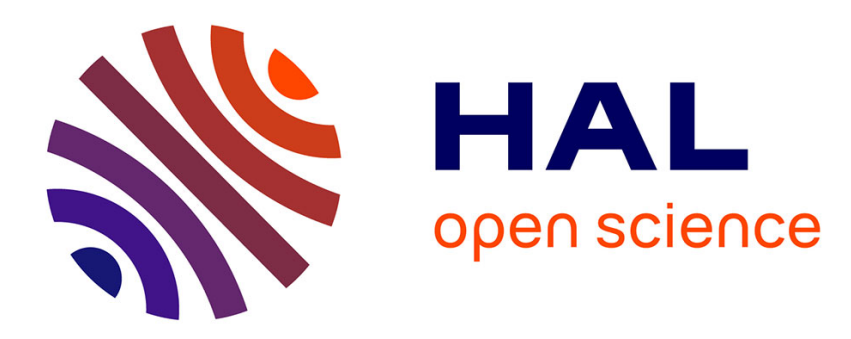

\title{
Optimum design of laminated composite structures
}

Christian Hochard

\section{To cite this version:}

Christian Hochard. Optimum design of laminated composite structures. Composite Structures, 2004, 63, pp.159-165. 10.1016/S0263-8223(03)00144-2 . hal-00088234

\section{HAL Id: hal-00088234 \\ https://hal.science/hal-00088234}

Submitted on 26 Nov 2017

HAL is a multi-disciplinary open access archive for the deposit and dissemination of scientific research documents, whether they are published or not. The documents may come from teaching and research institutions in France or abroad, or from public or private research centers.
L'archive ouverte pluridisciplinaire HAL, est destinée au dépôt et à la diffusion de documents scientifiques de niveau recherche, publiés ou non, émanant des établissements d'enseignement et de recherche français ou étrangers, des laboratoires publics ou privés. 


\title{
Optimum design of laminated composite structures
}

\author{
Ch. Hochard * \\ Laboratoire de Mécanique et d' Acoustique, 31 Chemin Joseph Aiguier, 13402 Marseille Cedex 20, France
}

The optimum design of laminated composite structures in terms of their strength is a complex task because many different mechanisms are involved in the damage and rupture to which these materials are subject. The great diversity of the damage mechanisms and their patterns of evolution makes it extremely difficult to estimate the strength margins. It is still impossible, for instance, to perform simulations on industrial structures made of unidirectional ply laminates up to rupture. The strategy adopted in this study on designing laminated composite structures is based on the choice of materials (woven or unidirectional plies) and the use of simple models (focusing on the rupture of the first ply) with which industrial structure analyses can be carried out. The choice of materials (woven or unidirectional plies) does not depend only on mechanical criteria but also on the simplicity of the corresponding modelling procedures.

Keywords: Laminated composite; Structure design; Damage; Woven ply

\section{Introduction}

The qualities for which laminated composites are mainly chosen are their specific rigidity and strength. Although designing structures according to rigidity does not raise any particular problems, designing with respect to strength is much more complicated. When these materials are subjected to severe loading up to rupture, the many mechanisms responsible for the damage and rupture occur on different scales: matrix micro-cracking, fibre/matrix debonding, transverse rupture, fibre rupture, delamination, rupture of the plies and the laminate [1]. The great diversity of the damage mechanisms and their patterns of evolution makes it extremely difficult to estimate the strength margins.

Models which describe the behaviour of these materials and tools for simulation which can be used to determine the evolution of the damage have been previously developed (e.g. Refs. [2,3]). However, these are very time-consuming (non-linear behaviour is used to describe the many mechanisms involved in rupture, and 3-D modelling to account for the edge effects). When transverse rupture and delamination occur in the edge zones of unidirectional (UD) ply laminates, they

\footnotetext{
${ }^{*}$ Tel.: +33-49111-3875; fax: +33-49111-3838.

E-mail address: hochard@unimeca.univ-mrs.fr (Ch. Hochard).
}

will extend inside the structure and it is therefore not yet possible (by performing 3-D modelling inside the structure) to simulate the damage processes occurring in complex industrial structures.

The strategy adopted in this study on designing laminated composite structures is based on the choice of materials (woven or UD plies, high modulus fibres) and the use of simple models (focusing on the rupture of the first ply) with which industrial structure analyses can be carried out. It is proposed here to study the following three cases, using this strategy:

(i) In the case of woven plies laminates, the number of damage mechanisms is fairly small (no transverse rupture occurs and the material has a greater resistance to delamination) and the behaviour of the material is fairly simple to model up to rupture [4]. A finite element calculation in terms of plane stresses which includes the plastic elastic damage behaviour of the woven ply makes it possible to describe the rupture of a structure.

(ii) For studying UD ply laminates under static and fatigue loading, a first ply failure model was previously proposed for structures not subject to delamination (Refs. [5,6]). Within this restricted framework, a model based on plane stresses accounting for the elastic plastic damage behaviour of the ply again turned out to be sufficiently. This 
type of model can be used for dealing with tubes, for example, in contexts where a high level of safety is required.

(iii) High modulus fibres (such as Dialead fibres) are suitable for applications where the rigidity is of particular importance (in the case of structures subjected to dynamic and buckling loading, for instance). For these applications, it suffices to use the elastic behaviour to be able to predict the rigidity. However, these fibres are not very resistant to compression and their response to high compression conditions therefore needs to be precisely determined.

\section{Woven ply laminates}

Woven ply laminates have weaker mechanical characteristics and are more expensive than UD ply laminates. They are used, however, in industry (to make helicopter blade skins, for example). The explanation often given by companies for this choice of woven ply laminates is that they are not subject to transverse rupture, which can be catastrophic in the case of UD plies. In addition, these materials are more resistant to delamination. The number of damage mechanisms liable to occur is thus reduced and the behaviour of the material is simpler to model up to rupture. A finite element calculation in terms of the plane stresses, which includes the plastic elastic damage behaviour of the woven ply material, can be used to describe the rupture of a structure of this kind (in general, the rupture of a ply leads to the rupture of the laminate in the case of woven plies). Comparisons are made between the results of a test and those of a finite element simulation involving a plate with a hole subjected to traction.

\subsection{Damage behaviour of balanced woven plies}

The behaviour of materials of this type and the modelling procedure used were previously described in
Ref. [4]. The material is reinforced with a carbon fabric of the four-harness satin type, with balanced warp and fill yarns. In the fibre directions, the woven ply shows a brittle linear elastic behaviour when subjected to tension (see Fig. 1(a)). The damage occurring in these directions does not affect the behaviour of the ply under traction loading. However, traction applied in the warp direction generates micro-cracks in the matrix within both the fill and warp yarns [4]. When shear loading was applied (from a tensile test on a [45] laminate), a decrease in the shear modulus as well as inelastic strains were observed (see Fig. 1(b)). The decrease in the modulus was due to the ply shear stress, which generated some fibre/matrix decohesion and matrix micro-cracks within the warp and fill yarns. The inelastic strains and the loading-unloading hysteresis observed (Fig. 1(b)) were mainly due to the slipping/friction processes occurring between the fibres and matrix as the result of the damage.

With a view to modelling the behaviour of laminates with a woven reinforcement, we have adapted the "meso-scale" model developed for unidirectional plies described in Ref. [7]. This model was designed for dealing with woven plies with balanced or non-balanced warp and fill yarns. The damage kinematics adopted were based on the following three internal damage variables $\left(d_{1}, d_{2}, d_{12}\right)$ : the brittle fracture of fibres in the warp and fill directions and the decreasing stiffness under shear loading $\left(G_{12}=G_{12}^{0}\left(1-d_{12}\right)\right)$, respectively. The gradual development of the damage $d_{12}$ depends on the shear load as well as on the traction load, which generates micro-cracks in both the fill and the warp components. These micro-cracks, which are mainly located at the fibre/matrix interfaces, are assumed to run parallel to the fill and warp directions. The tension energy and the compression energy are split in order to be able to describe the unilateral nature of the damage due to the opening and closing of the micro-defects.

Since the warp and fill fibre directions prevent inelastic traction strains from occurring, only the inelastic shear strains are significant here. These strains can be
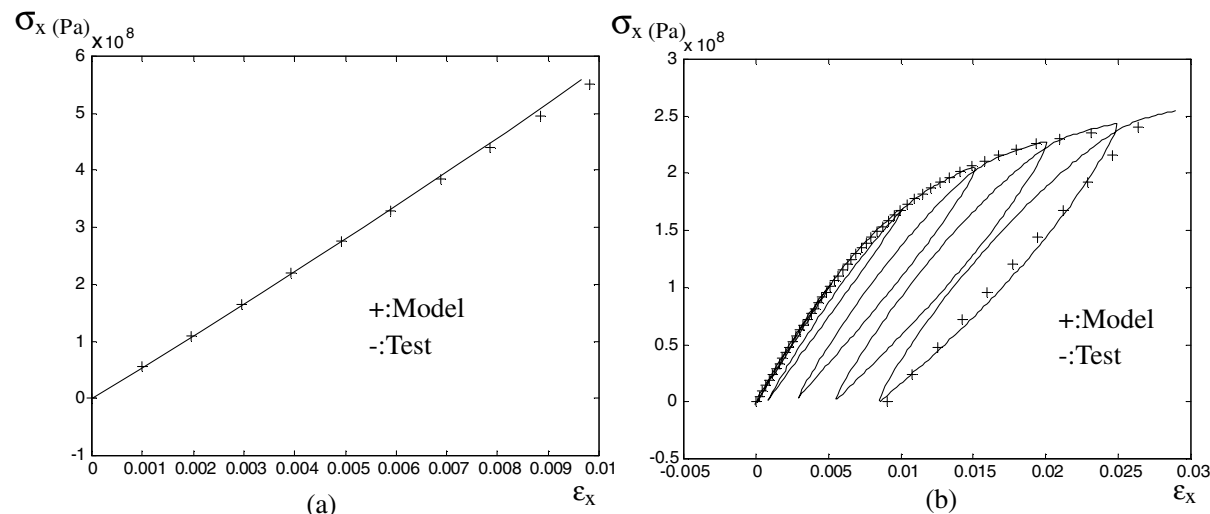

Fig. 1. Tensile tests on a $[0]_{8}$ (a) and $[45]_{8}$ (b) laminates. 
satisfactorily described by a plastic model. The loading/ unloading hysteresis, which is mainly due to the slipping/friction processes occurring between the fibres and the matrix, is not modelled. Tests were carried out with various materials (G802/914; G939/M18; G963/913) in order to check the validity of the model.

\subsection{Delamination behaviour of woven ply laminates}

In the case where a traction is applied to $[-\theta,+\theta]_{\mathrm{ns}}$ UD ply laminates with small $\theta$ values, modelling the ply alone does not suffice to be able to predict the rupture of the laminate $[3,7]$. The rupture results from delamination processes, which are three-dimensional effects starting on the edges of the specimen. This is not what happens in the case of woven ply laminates [4]. The resistance of woven ply laminates to delamination is mainly due to the fact that a $[-\theta,+\theta]_{\mathrm{ns}}$ woven ply laminate is equivalent to a $[-\theta,-\theta-90,+\theta, \theta+90]_{\mathrm{ns}}$ UD ply laminate, which is quite different from a $[-\theta,+\theta]_{\mathrm{ns}}$ UD ply laminate.

Another test was carried out on a $[+45,-45,0,90]_{s}$ woven ply laminate. Excellent correlations were obtained for the failure predictions (they were similar to those obtained on the $[0,45]_{2 \mathrm{~s}}$ laminate). In the case of unidirectional plies, the rupture of this type of laminate also results from delamination phenomena and modelling the ply alone does not make it possible to predict the rupture.

The standard delamination tests carried out (double cantilever beam (DCB), edge node flexure (ENF) and mixed mode flexure (MMF)) confirmed that woven ply laminates have a greater delamination resistance. Table 1 shows the critical energy release rate in laminates made of T300/914 unidirectional ply versus G802/914 woven ply. The great resistance of these materials to delamination may be due to the ondulations of the fabric wicks and to the resin pile located at the interfaces.

The high resistance of woven ply laminates to delamination, in addition to the fact that they are not subject to transverse rupture, makes it possible to simulate the behaviour of complex structures made of these materials up to rupture. For this purpose, a simple finite element model of the shell type, based on the plane stresses and accounting for the inelastic damage behaviour of the woven ply, can be used. This relatively

Table 1

Comparison of the critical energy release rate $\left(\mathrm{J} / \mathrm{m}^{2}\right)$ between $\mathrm{T} 300 / 914$ UD ply and G802/914 woven ply laminates

\begin{tabular}{llcc}
\hline Type of ply & $G_{\text {cI }}$ (DCB test) & $G_{\text {cII }}$ (ENF test) & $G_{\text {mixed }}$ (MMF test) \\
\hline $\begin{array}{c}\text { UD ply } \\
\text { (T300/914) }\end{array}$ & 180 & 440 & 237 \\
$\begin{array}{c}\text { Woven ply } \\
\text { (G802/914) }\end{array}$ & 400 & 2000 & 1130 \\
\hline
\end{tabular}

simple modelling procedure is not suitable in the case of UD plies, in which transverse rupture and delamination processes resulting from the 3-D effects mentioned above are the main factors responsible for the rupture of the laminate.

\subsection{Behaviour of a perforated plate subjected to tension}

In order to test the model, comparisons were made between the results of an experimental test and those of a simulation involving a perforated plate under traction loading. The perforated plate (Fig. 2) was a $[45]_{4}$ laminate made of woven plies.

Fig. 3 makes it possible to compare the measured strain (gauges g1, g2 and g3, Fig. 2) with the simulated strain (the mean strain on the surface of the gauge). It can be seen here that the breaking force and the strongly non-linear behaviour were accurately predicted by the model.

Fig. 4 gives the map of the measured strain (on the left) and that of the simulated strain (on the right) before rupture. The zone compared corresponds to the grey rectangle $\mathrm{R}$ in Fig. 2. The strain was measured using image processing methods [8]. The accuracy of the simulation and the very high levels of strain are worth noting. The simulation predicted very high levels of damage (more than 0.5). A further study is now being

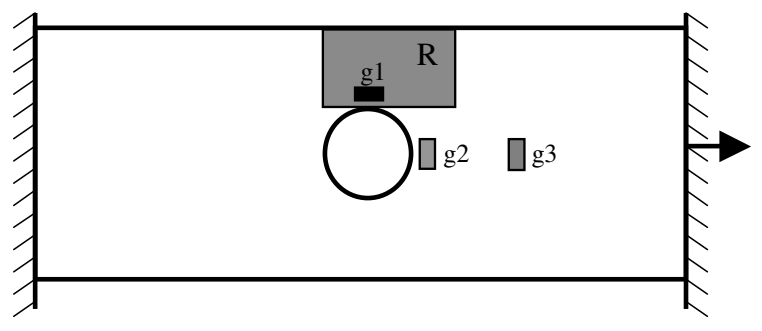

Fig. 2. Traction test on a perforated plate made of $[45]_{4}$ woven ply laminate.

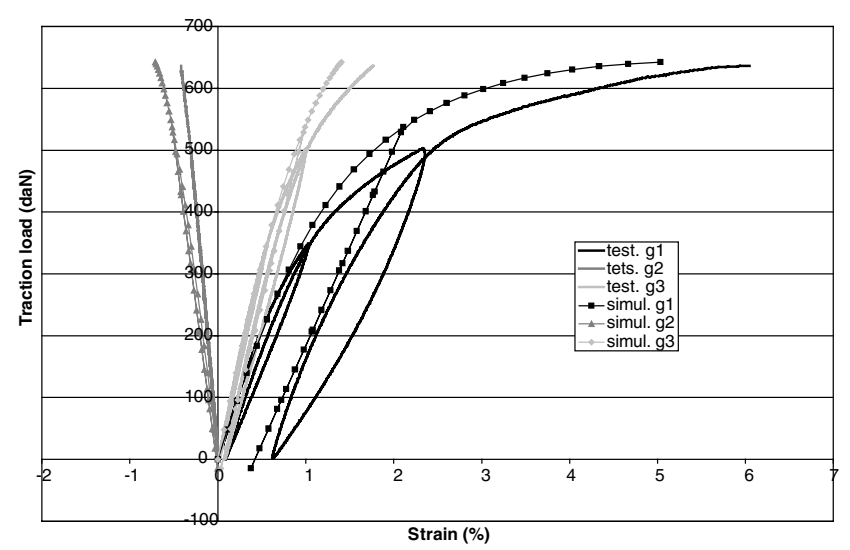

Fig. 3. Measured and simulated strains (see Fig. 2). 


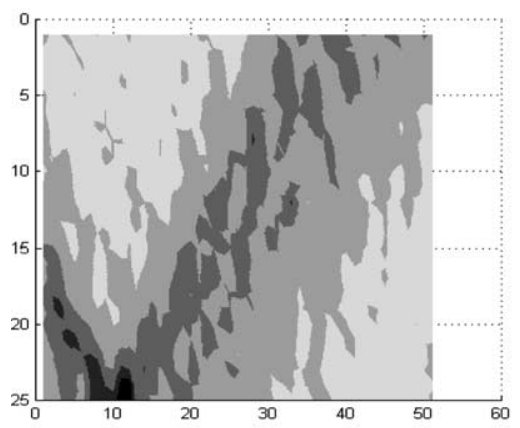

(a)
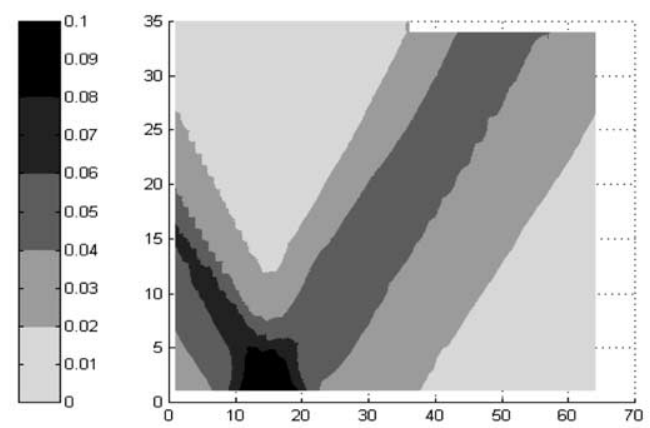

(b)

Fig. 4. Measured (a) and simulated (b) strain fields.

carried out in order to measure the damage levels involved [9].

\section{Fatigue behaviour}

For dealing with UD ply laminates, it was proposed to model the material up to rupture of the first ply in the case of structures or laminates which are not subject to delamination, under static and fatigue loading conditions [5,6]. Within this restricted framework, a model based on plane stresses accounting for the elastic plastic damage behaviour of the ply again turned out to be sufficiently. An original method of testing the transverse stress behaviour is presented.

\subsection{Behaviour of a unidirectional ply under static and fatigue loading}

The model previously presented $[5,6]$ is a non-linear cumulative damage model, which makes it possible to describe the development of damage under both static and fatigue loading conditions. The delamination processes are not accounted for in this model, which is therefore relevant only to some particular structures and laminates that are not subject to delamination (those which have no edges, as in the case of tubes, for example). The validity scope of the model described here depends on the 'diffuse damage' phase (which is associated with micro-cracks) up to the first intra-laminar macro-crack only. In this respect, the modelling procedure adopted differs from the approaches which describe the macro-crack density $[10,11]$. This type of model can be used in contexts where a high level of safety is required.

The material is assumed to be brittle and non-sensitive to the cyclic loading occurring in the direction of the fibres. The plane transversal and shear moduli are modified under the assumption that a gradual damage process is involved, via the micro-cracks running parallel to the fibres. The development of the damage de- pends on the maximum static and cyclic loads and their amplitude as well as on the level of damage involved. In the case of a transverse compression load, the microcracks close up and thus the transverse behaviour remains undamaged.

After a loading process has taken place in a laminate, residual strains can be observed. These strains can be due to the friction occurring between the fibres and the matrix as the result of the damage. To describe them, an kinematic hardening model is under development. This type of anelastic damage behaviour was studied by performing traction tests and 4 point bending tests. The samples used in the bending test were sandwich structures (a laminate with the ply studied forming one skin, a honeycomb, and a woven ply laminate at $0^{\circ}$ forming the other skin). With this sandwich structure, it is possible to create an almost uniform state of strain in the ply studied, and the woven plies are assumed to undergo almost no degradation. One of the advantages of the four point bending test is that it makes it possible to prescribe a compression load on the ply under investigation.

Tests with prescribed forces and prescribed strains were performed under fatigue loading, and the effects of the various model parameters were analysed [5,6]. A example of the evolution of the damage process in the case of a traction/traction fatigue test on a $\left[ \pm 45^{\circ}\right]_{\mathrm{ns}}$ laminate is shown in Fig. 5. The first level of damage $(d=0.3)$ was found to occur during the first cycle. The damage then increases slowly at each cycle, and the speed of evolution gradually increases until rupture occurs. In the simulation, the rupture of a $\left[ \pm 45^{\circ}\right]_{\mathrm{ns}}$ laminate was obtained by introducing a structure instability condition. Under static loading, this condition corresponds to a damage value $d=0.5$, although this value can be greater under fatigue loading. This result is in line with what has been observed experimentally.

Another comparison between simulations and tests (Ref. [12]) on $\left[ \pm 45^{\circ}\right]_{\mathrm{ns}}$ laminates under fatigue loading showed the possibilities of the model (Fig. 6). The results of the simulations carried out with different stresses and 


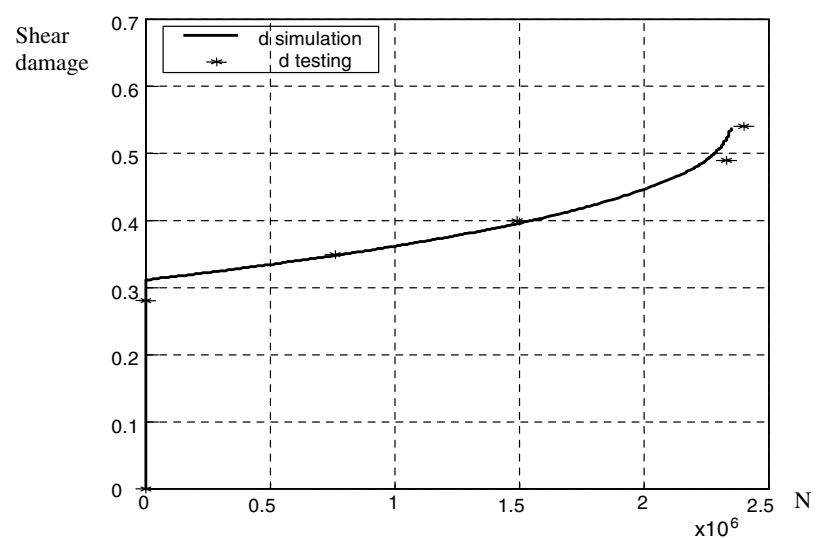

Fig. 5. Testing and simulation of damage evolution (fatigue loading, $\sigma_{\max }=120 \mathrm{MPa}$, stress ratio $R=0.5$ ).

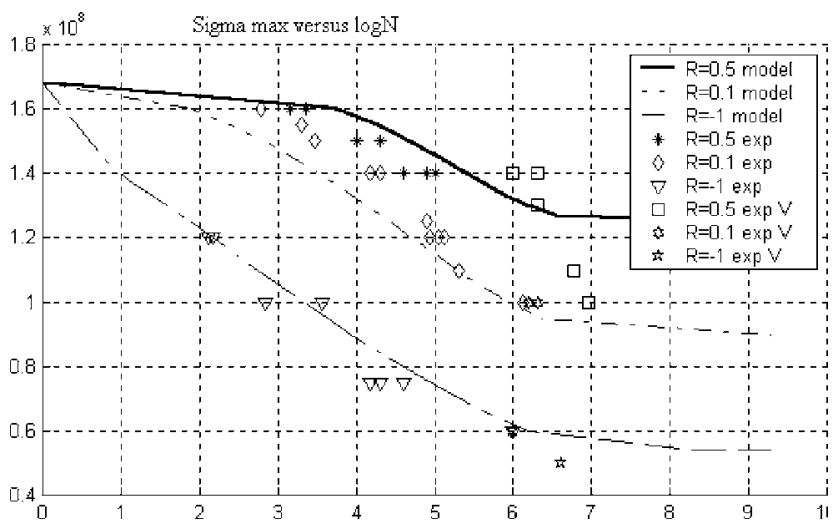

Fig. 6. Fatigue behaviour on $[ \pm 45]_{\text {ns }}$ laminates (tests from Petermann and Schulte Ref. [12]).

stress ratios (minimum stress over maximum stress) were in good agreement with the experimental results. The endurance limits were found to vary with respect to the stress ratios in the case of both the model and the experiments (the notation "exp V" corresponds to specimens which did not break).

\subsection{Transverse behaviour of UD plies}

In the case of UD plies, the transverse behaviour is characterised by a maximum threshold damage beyond which the first intra-laminar rupture appears. The traditional tensile test on a $\left[90^{\circ}\right]_{\mathrm{ns}}$ laminate is very unstable and does not reflect the behaviour of material accurately when it is confined within the laminate. There exist some more accurate methods of testing the transverse behaviour, such as those consisting of applying tension to $\left[45^{\circ}\right]_{\mathrm{ns}}$ or $[+67.5,-67.5]_{\mathrm{ns}}$ laminates [7]. However, in these tests, the evolution of the damage depends not only on the transverse stress but also on the shear stress. This coupling makes it more difficult to identify the transverse behaviour. We previously proposed a test

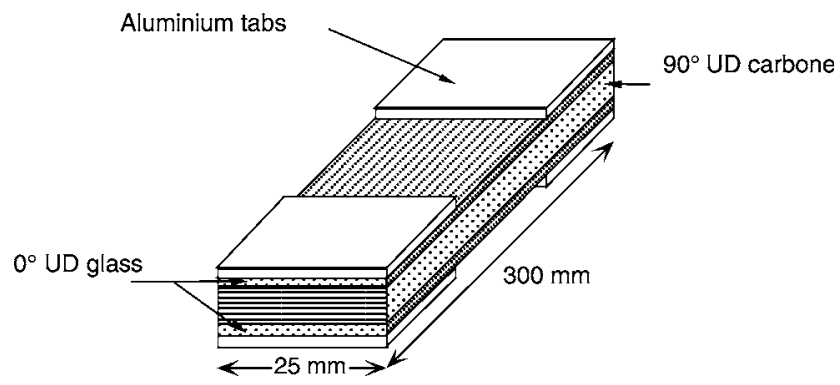

Fig. 7. Hybrid $\left[90^{\circ}\right]$ carbon $/\left[0^{\circ}\right]$ glass specimen.

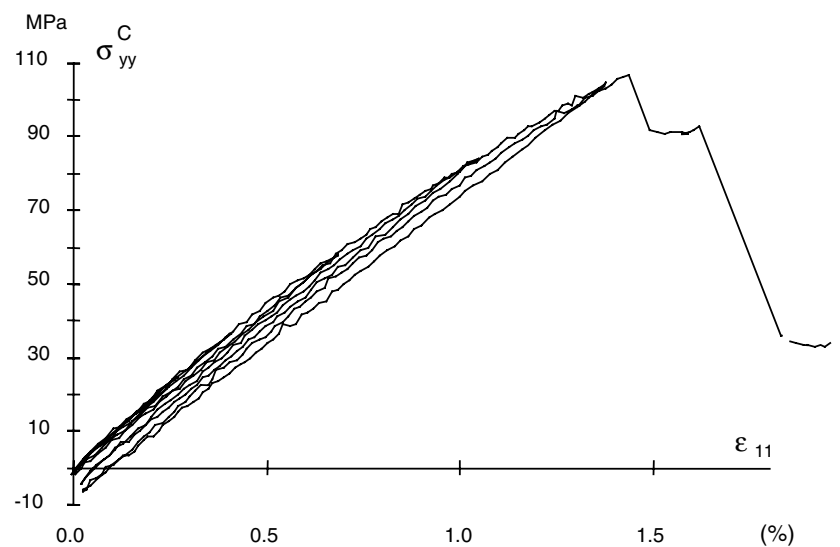

Fig. 8. Transverse behaviour for G827/914 unidirectional ply.

using a hybrid glass/carbon laminate including $\left[90^{\circ}\right]_{16}$ carbon plies placed between two $\left[0^{\circ}\right] \mathrm{R}$-glass/epoxy plies (Fig. 7). The advantage of this hybrid configuration is that the plies of glass maintain the carbon plies and prevent them from breaking prematurely. Glass fibres were chosen instead of carbon fibres because of their relatively low stiffness and because the intra-laminar macro-cracks in the $90^{\circ}$ carbon plies can be easily detected. From the overall behaviour of the laminate and the behaviour of the R-glass ply alone, it is possible to deduce the transverse behaviour of the carbon ply. Fig. 8 shows the transverse stress/strain curve in the carbon plies after calculations based on the tension test on the hybrid laminate. Note the high levels of rupture strain $(1.3 \%)$ and damage $(0.2)$ occurring in this material (G827/914).

The first fatigue tests performed in the transverse direction seem to indicate that there exists a threshold stress level below which the damage does not increase and that the rupture can be defined by the maximum damage [6].

\section{High modulus fibres}

The latest high modulus fibres (such as Dialead fibres) lend themselves well to applications where the 
rigidity is of great importance (in the case of structures subjected to dynamic and buckling loading, for instance). In this case, it can suffice to model the material in terms of its elastic behaviour. However, these fibres are not very resistant to compression forces and their behaviour under high compression conditions therefore needs to be precisely determined.

\subsection{High modulus fibres for high rotation frequency tubes}

The performances of high rotation frequency tubes (such as drive shafts and centrifugal machines) can be improved by using high rigidity carbon fibres, the effective modulus of which can be eight times greater than that of steel. A high effective modulus makes it possible to delay the onset of the vibration modes. The buckling strength under torsion, which is one of the main criteria used in designing drive shafts [13], can also be greatly improved by using these fibres. For these applications, it can suffice to model the material in terms of its elastic behaviour according to dynamic and buckling design. It is worth noting that materials of this kind with very high modulus have a very low breaking strain in the fibre direction, which is even lower than that observed in the transverse direction. In laminates where the plies undergo shearing and compression stresses in the fibre direction, elastic criteria can be used to describe the rupture of the laminate under static loading conditions.

Rupture behaviour under compression loading in the fibre direction is more difficult to predict. The standard tests consisting of applying pure compression (Celanese) predict the occurrence of the rupture prematurely because of the edge effects and the buckling of the specimen. Compression tests on $\left[+60_{2}, 0,-60_{2}\right]_{\mathrm{s}}$ laminates [14] have been developed which make it possible to decrease the risk of buckling in the specimen. In these compression tests, the calculation of the stresses in the $0^{\circ}$ plies is rather complex, however, due to the non linear behaviour of the $60^{\circ}$ plies. Buckling/bending tests [15] and four point bending tests also make it possible to determine the rupture strain under compression loading. However, these bending tests do not yield any direct information about the stresses in the beam (the inverse calculations are complex due to the large displacements and rotations involved).

A pure bending test has been proposed (Fig. 9) for determining the compression behaviour more precisely. This test, which consists in applying two bending couples at the two free ends and letting one of the ends translate freely, makes it possible to determine the forces at work (constant moment) throughout the sections. In addition, it is possible here to use machined specimens (Fig. 9) in order to rule out the occurrence of edge effects at the level of the tabs.

The behaviour of two materials undergoing compression forces has been studied (M55J, Dialead K63712). In

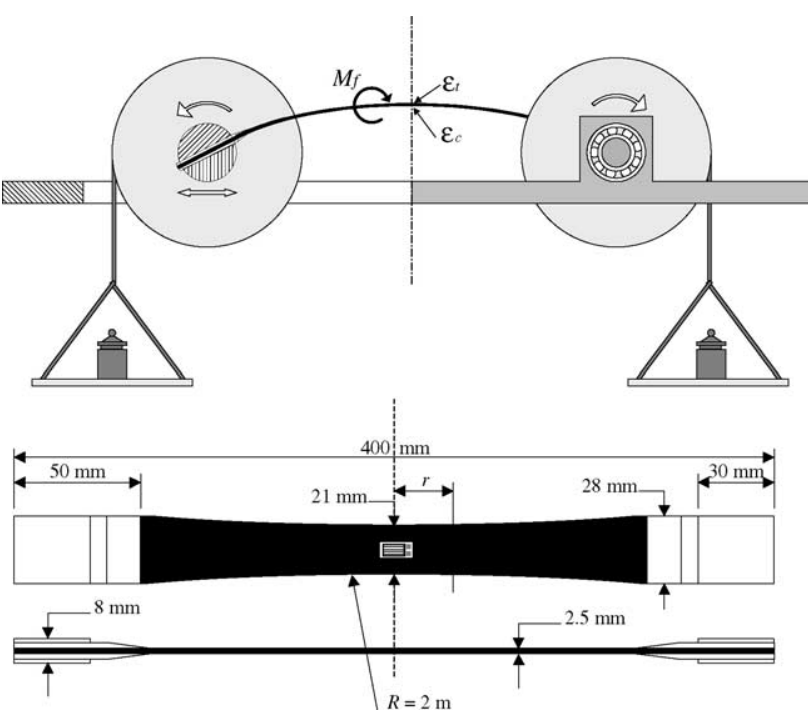

Fig. 9. Diagram and specimen for pure bending test.

Moment (mN)

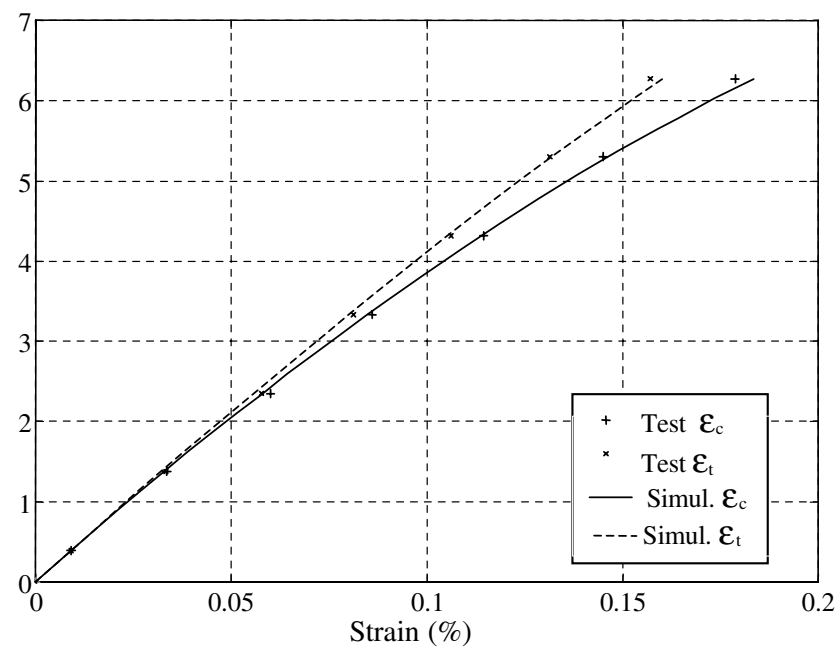

Fig. 10. Pure bending test on unidirectional Dialead K63712 $\left(\varepsilon_{\mathrm{c}}\right.$ : compression face; $\varepsilon_{t}$ : traction face).

both cases, this behaviour is elastic and non-linear (the rigidity decreases under compression, see Fig. 10). To model this non-linear behaviour, the rigidity was taken to decrease under compression depending on the deformation. As under shear loading, the rupture under compression seems to involve a process of instability.

\section{Conclusion}

In conclusion, two simple rules emerge from the results of this study as far as the technological design of laminated composite structures is concerned: 
- It is recommended to use woven plies to design structure according to strength.

- It is recommended to use UD plies to design structure according to rigidity - or to strength, but only up to failure of the first ply and for structures which are not subject to delamination.

The choice of type of ply (woven or unidirectional plies) does not depend only on mechanical criteria but also on the simplicity of the corresponding modelling procedures.

\section{References}

[1] Reifsnider K. Durability and damage tolerance of fibrous composite systems. In: Peters ST, editor. Handbook of composites. 2nd ed. Chapman \& Hall; 1998. p. 794-809.

[2] Ladevèze P. Modelling and computation until final fracture of laminate composites. In: Recent Developments in Durability Analysis of Composite Systems, Proceedings of the Fourth International Conference, DURACOSYS 99, Brussels, 2000. p. $39-47$.

[3] Phillips EA, Herakovich CT, Graham LL. Damage development in composites with large stress gradient. Compos Sci Technol 2001;61:2169-82.

[4] Hochard C, Aubourg PA, Charles JP. Modelling of the mechanical behaviour of woven-fabric CFRP laminates up to rupture. Compos Sci Technol 2001;61:221-30.
[5] Hochard C, Payan J. Endommagement de composites stratifiés carbone/epoxy sous chargement statique et de fatigue. Rev Compos à Matrice Organ 2001;11(3):333-48.

[6] Payan J, Hochard C. Damage modelling of carbon/epoxy laminated composites under static and fatigue loads. Int $\mathrm{J}$ Fatigue 2002;24:299-306.

[7] Ladevèze P, Le Dantec E. Damage modelling of the elementary ply for laminates composites. Compos Sci Technol 1992;43(3): 257-68.

[8] Chevalier L, Calloch S, Hild F, Marco Y. Digital image correlation used to analyze the multiaxial behavior of rubber-like materials. Eur J Mech A/Solids 2001;20(2):169-87.

[9] Bois C, Hochard C. Measurements and modelling for the monitoring of damage in laminated composites structures. In: Proceedings of the First European Workshop on Structural Health Monitoring, Cachan, 2002. p. 425-32.

[10] Akshantala NV, Taljera R. A micromechanics based model for predicting fatigue life of composite materials. Mater Sci Eng A 2000;285:303-13.

[11] Lafarie-Frenot MC, Hénaff-Gardin C, Gamby D. Matrix cracking induced by cyclic ply stresses in composite laminates. Compos Sci Technol 2001;61:2327-36.

[12] Petermann J, Schulte K. Strain based service time estimation for angle-ply laminates. Compos Sci Technol 2002;62:1043-50.

[13] Bert CW, Kim CD. Analysis of hollow laminated composite drive shafts. Compos Sci Technol 1995;53:343-51.

[14] Welsh JS, Adams DF. Testing of angle-ply laminates to obtain unidirectional composite compression strengths. Compos Part A 1997;28:387-96.

[15] Wisnom MR. On the high compressive strains achieved in bending tests on unidirectional carbon-fibre/epoxy. Compos Sci Technol 1992;43:229-35. 